\title{
Absences attributed to respiratory diseases in welders
}

\author{
R F FAWER,*1 A WARD GARDNER, ${ }^{2}$ AND D OAKES 1 \\ From TUC Centenary Institute of Occupational Health, ${ }^{1}$ London School of Hygiene and Tropical Medicine, \\ London WC1E 7HT, and Esso Medical Centre, ${ }^{2}$ Fawley, Southampton SO4 1TX, UK
}

ABSTRACT Certified sickness rates of 36 male welders were examined for the period 1970-9. They were compared with 36 male controls from the same petrochemical plant, matched for age, smoking habits, duration of employment, and social class. Indices of severity (average annual duration), duration (average length of spell), and frequency (inception rate of spells and inception rate per worker) were calculated. Absences for all diseases were similar, but absences attributed to respiratory diseases were slightly higher in welders in severity, duration, and frequency. The proportion of days lost attributed to respiratory diseases was $2 \cdot 3$ times higher in welders compared with controls. This was due to a large increase in absences attributed to lower respiratory tract diseases, the ratio of welders to controls being more than four to one for both severity and inception rate of spells. The comparison between welders and controls in smokers and non-smokers confirms other studies which show that smokers tend to be more affected by welding fumes than non-smokers.

The possible harmful effects of low concentrations of welding fumes have been discussed for many years and the results of previous investigations are somewhat contradictory. ${ }^{1}$

The objectives of the present retrospective followup study were to compare the absence rates attributed to respiratory tract diseases in welders and in matched controls during a ten-year period.

\section{Material and methods}

\section{SUBJECTS}

All welders who had worked in a petrochemical plant for more than one year between 1 January 1970 and 31 December 1979 were identified. Of the 50 welders who had worked at some time during this ten-year period 14 were not included in the study, 13 because they had started after 1 January 1979 (and therefore had worked less than one year) and one because of lack of information. The study population, therefore, comprises 36 welders.

The control population of 36 men was selected from the same social class ${ }^{2}$ (pipefitters, boiler-

\footnotetext{
*Present address: Occupational Health and Industrial Hygiene Service, Bellevaux 51, 2000 Neuchâtel, Switzerland. Requests for reprints to Dr A Ward Gardner.

Received 1 April 1981

Accepted 5 August 1981
}

makers, mechanical and electrical fitters) within the same petrochemical plant. Each control was matched for date of birth ( \pm 3 years), duration of employment between 1 January 1970 and 31 December 1979, date of starting in the company $( \pm 5$ years), degree of fitness at the pre-employment examination, and smoking habits. When two or more controls were available, a random number table was used. $^{3}$

\section{EXPOSURE TO FUMES}

There were insufficient records of dust and fume levels to permit reliable and complete estimation of exposure to fumes during the period under study. Welders do mainly electric arc welding. Measurements in an open shop without local exhaust on mild steel with stick electrodes showed a concentration in the breathing zone of total fumes of $3-4 \mathrm{mg} / \mathrm{m}^{3}$; the present TLV is $5 \mathrm{mg} / \mathrm{m}^{3}{ }^{4}$ Investigations undertaken since the results of this study became known have shown occasional levels up to five times the TLV for total fumes in confined space work and work practices have been modified accordingly.

\section{SICKNESS ABSENCE RECORDS}

A copy of the diagnosis given by the employee's general practitioner is sent to the medical centre where it is stored in the medical records. The diagnoses are not systematically validated, but each 
employee is reviewed by the medical centre after being absent for more than three days.

The starting date of each absence, the number of days lost, and the diagnosis were extracted from company medical records. The diagnosis was coded according to the International Classification of Diseases, eighth revision. ${ }^{5}$ Only certificated absences of more than three days were recorded. Absences attributed to reasons other than sickness (injuries and attendances at hospitals or dentists) were excluded.

Absences attributed to the categories below were selected for study:

all diseases (ICD 000.0-796.9)

all respiratory diseases (ICD 460-519.9)

upper respiratory tract diseases (ICD 460-465, 500-508)

lower respiratory tract diseases (ICD 466: acute bronchitis; ICD 480-486: pneumonia; ICD 490-493: bronchitis, emphysema and asthma; ICD 510-519: other diseases of respiratory system: empyema, pleurisy, abscess of lung, bronchiectasis, pneumoconiosis ...)

digestive diseases (ICD 009.0, 009.2-009.9, 520577.9, 785.0-785.8).

Digestive diseases were chosen as a control subgroup because they are thought to be unrelated to welding fumes. Therefore no differences should be noticed between welders and controls for absences attributed to these conditions and any tendency towards overreporting might be detected.

Table 1 General characteristics of the study population

\begin{tabular}{lll}
\hline & $\begin{array}{l}\text { Welders } \\
(n=36)\end{array}$ & $\begin{array}{l}\text { Controls } \\
(n=36)\end{array}$ \\
\hline Age* (mean and range) (years) & $49 \cdot 2(22-64)$ & $48 \cdot 9(23-64)$ \\
Duration of employment & $7 \cdot 1 \quad(1-10)$ & $7 \cdot 1 \quad(1-10)$ \\
$\quad$ (mean and range) (years) & 14 & 14 \\
$\quad$ Nmoking habits: & 2 & 2 \\
$\quad \begin{array}{l}\text { Non-smokers } \\
\text { Ex-smokers }\end{array}$ & 20 & 20 \\
$\quad$ Expokers & $25 \cdot 9(4-42)$ & - \\
\hline (mean and range) (years) & & \\
\hline
\end{tabular}

*Defined as median year of the study period minus year of birth. $\dagger$ Defined as median year of the study period minus year of starting welding.

\section{ANALYSIS AND STATISTICS}

Taylor $^{6}$ suggests four indices of absence.

Average annual duration per worker a year (days)Sum of all days of absence in the period divided by the number of man-years in the period (index of severity).

Average length of spell (days)-Sum of days of absence in the period divided by the sum of spells in the period (index of duration).

Inception rate of spells-Number of the total new spells in the period divided by the number of manyears in the period (index of frequency).

Inception rate per worker-Proportion of workers having one or more new spells in the period divided by the number of men in the period (index of frequency).

The statistical differences between the first three indices have been evaluated by the Wilcoxon rank test for paired data and those in inception rate per worker by the McNemar test.?

\section{Results}

Table 1 shows the general characteristics of the study population. Two-thirds were over 50; of the welders, two-thirds had been welding for more than 20 years. There were no deaths during employment, and seven welders left employment in welding during the tenyear study period, all for retirement at the normal age of 65 .

Table 2 shows that for all diseases the three indices of severity, duration, and frequency were similar in welders and in controls. Welders have slightly higher rates than controls for average annual duration of spells, average length of spells, and inception rate of spells for absences due to all respiratory diseases.

The proportion of days lost and the number of spells for absences attributed to all respiratory diseases related to absences attributed to all diseases is shown in table 3. Both proportions are higher in welders than in controls; the differences are statistically significant.

For upper respiratory tract diseases, the three indices of severity, duration, and frequency are

Table 2 Absences attributed to all diseases and to all respiratory diseases

\begin{tabular}{|c|c|c|c|c|}
\hline \multirow[t]{2}{*}{ Absence measurement } & \multicolumn{2}{|c|}{ All diseases } & \multicolumn{2}{|c|}{ All respiratorv diseases } \\
\hline & Welders & Controls & Welders & Controls \\
\hline $\begin{array}{l}\text { Average annual duration (days) } \\
\text { Average length of spell (days) } \\
\text { Inception rate of spells } \\
\text { Inception rate per worker }\end{array}$ & $\begin{array}{c}13 \cdot 2 \\
17 \cdot 3 \\
0 \cdot 76 \\
0 \cdot 79\end{array}$ & $\begin{array}{c}12 \cdot 4 \\
18 \cdot 5 \\
0 \cdot 67 \\
0 \cdot 83\end{array}$ & $\begin{array}{c}7 \cdot 4 \\
15 \cdot 0 \\
0 \cdot 49 \\
0 \cdot 78\end{array}$ & $\begin{array}{l}2 \cdot 9^{*} \\
10 \cdot 8^{*} \\
0 \cdot 27^{*} \\
0 \cdot 61\end{array}$ \\
\hline
\end{tabular}

$* p<0 \cdot 10$. 
Table 3 Proportion of days lost and spells for absences attributed to all respiratory diseases related to absences attributed to all diseases

\begin{tabular}{lll}
\hline & Welders & Controls \\
\hline Days lost & 0.56 & $0 \cdot 24^{* * *}$ \\
No of spells & 0.65 & $0 \cdot 40^{* *}$ \\
\hline
\end{tabular}

${ }^{* *} \mathrm{p}<0.05 ;{ }^{* * *} \mathrm{p}<0.025$.

similar in welders and controls (table 4). For lower respiratory tract diseases, however, welders have an average annual duration of absence 4.6 times that of controls, and an inception rate of spells of absence 5.0 times greater. These differences are statistically significant $(\mathrm{p}<0.01)$. The inception rate per welder is 2.8 times that of the controls, and this difference is also statistically significant $(\mathrm{p}<0.025)$. The average length of spells is similar in welders and controls.

No differences were found between welders and controls in absences attributed to digestive diseases and in absences attributed to all other causes.

Table 5 shows the severity and frequency of absences attributed to lower respiratory tract diseases in smoking and non-smoking welders and controls. The average annual duration of absence for welders who smoke is 4.8 times that of the controls who smoke, and the average annual duration of absence for non-smoking welders is twice that of nonsmoking controls. The inception rate of spells of absence in welders who smoke is $\mathbf{5 . 3}$ times that of controls who smoke and, for non-smoking welders, is $2 \cdot 7$ times that of non-smoking controls.

\section{Discussion}

This study of 36 welders and 36 matched controls has shown that their sickness absence rates for all diseases were similar. Their indices for all respiratory diseases differed only slightly (table 2 ). The proportions of days lost and number of spells of absences attributed to all respiratory diseases related to absences attributed to all diseases, however, were both higher in welders than in controls (table 3). This was mainly due to higher severity and frequency indices for lower respiratory tract diseases in welders than in controls, the indices for upper respiratory tract diseases being similar (table 4).

This investigation confirms in part two previous reports. ${ }^{8} 9$ The results provided by Doig and Duguid $^{8}$ are difficult to compare with the present study because only the average annual duration of sickness absence per worker a year was given. Durations were not higher in welders than in other occupations, but the authors did not standardise either for age or for smoking habits.

McMillan ${ }^{9}$ studied 275 welders compared with five different groups of 1495 craftsmen in a naval dockyard. The total period of study was five years, and all men who left the plant during this period were included until their leaving date. For absences attributed to lower respiratory tract diseases, standardised figures for age and smoking habits showed that welders have more days off and higher inception rates than average; however, the differences were less than those observed in the present study. Contrary to our results, the average length of spell was highest among welders. The differences between these studies could be due to different distributions of age and smoking habits.

Beaumont and Weiss ${ }^{10}$ found an excess mortality from pneumonia in welders. In our study four welders but no controls had absences attributed to pneumonia.

All studies based on sickness absences look at an

Table 4 Absences attributed to upper and lower respiratory tract diseases

\begin{tabular}{|c|c|c|c|c|}
\hline \multirow[t]{2}{*}{ Absence measurement } & \multicolumn{2}{|c|}{ Upper respiratory tract diseases } & \multicolumn{2}{|c|}{ Lower respiratory tract diseases } \\
\hline & Welders & Controls & Welders & Controls \\
\hline $\begin{array}{l}\text { Average annual duration (days) } \\
\text { Average length of spell (days) } \\
\text { Inception rate of spells } \\
\text { Inception rate per worker }\end{array}$ & $\begin{array}{c}2 \cdot 3 \\
12 \cdot 2 \\
0 \cdot 19 \\
0 \cdot 50\end{array}$ & $\begin{array}{l}1 \cdot 2 \\
8 \cdot 5 \\
0 \cdot 15 \\
0 \cdot 47\end{array}$ & $\begin{array}{c}3 \cdot 7 \\
18 \cdot 3 \\
0 \cdot 20 \\
0 \cdot 47\end{array}$ & $\begin{array}{l}0 \cdot 8^{* * * * *} \\
17 \cdot 7 \\
0 \cdot 04^{* * * * *} \\
0 \cdot 19 * * *\end{array}$ \\
\hline
\end{tabular}

$* * * \mathrm{p}<0.025 ; * * * * \mathrm{p}<0.01$

Table 5 Severity and frequency of absences attributed to lower respiratory diseases in welders and controls with regards to their smoking habits (only subjects having worked throughout the ten-year study period)

\begin{tabular}{|c|c|c|c|c|}
\hline & \multicolumn{2}{|l|}{ Smokers } & \multicolumn{2}{|c|}{ Non-smokers } \\
\hline & $\begin{array}{l}\text { Welders } \\
(n=13)\end{array}$ & $\begin{array}{l}\text { Controls } \\
(n=13)\end{array}$ & $\begin{array}{l}\text { Welders } \\
(n=6)\end{array}$ & $\begin{array}{l}\text { Controls } \\
(n=6)\end{array}$ \\
\hline $\begin{array}{l}\text { Average annual duration (days) } \\
\text { Inception rate of spells }\end{array}$ & $\begin{array}{l}4 \cdot 3 \\
0 \cdot 21\end{array}$ & $\begin{array}{l}0 \cdot 9 \\
0 \cdot 04\end{array}$ & $\begin{array}{l}2 \cdot 2 \\
0 \cdot 16\end{array}$ & $\begin{array}{l}1 \cdot 1 \\
0.06\end{array}$ \\
\hline
\end{tabular}


indirect measure of morbidity, and many factors apart from disease, are known to influence absences attributed to sickness. ${ }^{61112}$ These factors include social class, age, smoking habits, and duration of service, for all of which welders and controls have been matched. Other factors have not been controlled-for example, attitude of supervisors, personality, and job satisfaction.

Finally, imperfections in the present study include uncertainty in diagnosis and lack of knowledge of the time and concentration of exposure to welding fumes. Welders perhaps think of themselves "at risk." This might cause them to take more sickness absence and could influence their GP's diagnosis. No differences, however, were found between welders and controls in absences attributed to digestive diseases (taken as control subgroup) and no tendency towards overreporting has been detected. Also each employee is reviewed by the medical centre after being absent for more than three days. It is therefore thought that no significant bias has been introduced.

Table 5 shows that although the number of workers is small the differences in severity and frequency for absences attributed to lower respiratory tract diseases between welders and controls are larger among smokers than among non-smokers. These results are consistent with the hypothesis ${ }^{1}$ that the recognised harmful effect of smoking and the possible harmful effect of welding fumes go together. This has also been shown with regard to lung function tests and symptoms of bronchitis by many authors, ${ }^{13-15}$ although a recent report did not confirm this point. ${ }^{16}$

The present study, although based on small numbers and looking at an indirect measure of morbidity, has shown that all results point to the same conclusion: compared with controls, welders have more absences attributed to respiratory diseases, especially lower respiratory tract diseases, and cigarette smoking enhances this. These results give some evidence of a probable harmful effect of welding fumes on the respiratory tract.
We thank Mrs Eve Williams, Esso Medical Centre, for expert clerical help.

RFF is the recipient of the grant 83.751.0.79 from the Swiss National Science Foundation.

This study formed part of the work submitted by RFF to the London School of Hygiene and Tropical Medicine for the degree of Master of Science in Occupational Medicine.

\section{References}

${ }^{1}$ Challen PJR. Some news on welding and welders. $J$ Soc Occup Med 1974;24:38-47.

2 Office of Population Censuses and Surveys. Occupational mortality. Decennial supplement 1970-2. London: HMSO, 1978.

${ }^{3}$ Geigy R. Scientific tables. 7th French ed. Basle: Geigy, 1972:131.

${ }^{4}$ Health and Safety Executive. Threshold limit values for 1979. Guidance note EH 15/79. London: HMSO, 1980.

${ }^{5}$ World Health Organisation. International classification of diseases. 8th rev. Geneva: WHO, 1967.

6 Taylor PJ. Aspects of sickness absence. In: Ward Gardner A, ed. Current approaches of occupational medicine. Bristol: Wright, 1979:322-38.

${ }^{7}$ Armitage P. Statistical methods in medical research. Oxford: Blackwell, 1971.

${ }^{8}$ Doig AT, Duguid LN. The health of welders. London: HMSO, 1951.

${ }^{9}$ McMillan GHG. Studies of the health of welders in naval dockyards. Ann Occup Hyg 1978;21:377-92.

${ }^{10}$ Beaumont JJ, Weiss NS. Mortality of welders, shipfitters, and other metal trades workers in boilermakers Local No 104, AFL-CIO. Am J Epidemiol 1980;112:775-86.

11 Taylor PJ. Sickness absence: facts and misconceptions. $J R$ Coll Physicians Lond 1974;8:315-33.

${ }^{12}$ Rushmore CH, Youngblood SA. Medically-related absenteeism: random or motivated behaviour? JOM 1979;21:245-50.

${ }^{13}$ Fogh A, Frost J, Georg J. Respiratory symptoms and pulmonary function in welders. Ann Occup Hyg 1969;12: 213-8.

14 Hunnicutt TN, Cracovaner DJ, Myles JT. Spirometric measurements in welders. Arch Environ Health 1964;8: 661-9.

${ }^{15}$ Oxhoj H, Bake B, Wedel H, Wilhelmsen L. Effects of electric arc welding on ventilatory lung function. Arch Environ Health 1979;34:211-7.

${ }^{16}$ Akbarkhanzadeh F. Long-term effects of welding fumes upon respiratory symptoms and pulmonary function. JOM 1980;22:337-41. 